\title{
Borderline Resectable Pancreatic Adenocarcinoma
}

National Cancer Institute

\section{Source}

National Cancer Institute. Borderline Resectable Pancreatic Adenocarcinoma. NCI

Thesaurus. Code C157350.

A pancreatic adenocarcinoma term that refers to a continuum between resectable and locally advanced unresectable disease. 